\title{
Improving Documentation of Pediatric Overweight and Obesity by
}

\section{Resident Physicians}

Introduction

Methods

Results

Conclusions

References
-Pediatric overweight and obesity have increased in prevalence over the last few decades.

- Despite expert guidelines that provide recommendations on pediatric overweight/obesity screening, prevention, and management, these disorders are underdiagnosed, and providers often deviate from expert guidelines.

-The appropriate education of resident physicians, who serve as frontline providers for many patients and play an important role in caring for them, is critical.

-The objective was to evaluate the effectiveness of resident-focused educational interventions on the screening and management of pediatric overweight and obesity by resident physicians. 


\section{Improving Documentation of Pediatric Overweight and Obesity by}

Resident Physicians

Vickie Wu, MD; Carolyn Rosen, MD; Leora Mogilner, MD

Introduction

Methods

Results

Conclusions

References
-Design: two months pre-intervention and two months postintervention chart reviews of preventive visits conducted by pediatric residents at an academic continuity practice.

- Charts of patients 2-18 years old with $\mathrm{BMI} \geq 85^{\text {th }}$ percentile for age and sex at the visit were reviewed (overweight: BMI $85^{\text {th }}$ to $<95^{\text {th }}$ percentile; obesity: $\mathrm{BMI} \geq 95^{\text {th }}$ percentile). 


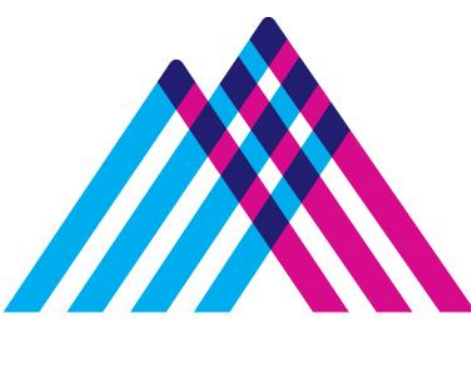

Icahn

School of

Medicine at

Mount

Sinai

\section{Improving Documentation of Pediatric Overweight and Obesity by} Resident Physicians

Vickie Wu, MD; Carolyn Rosen, MD; Leora Mogilner, MD
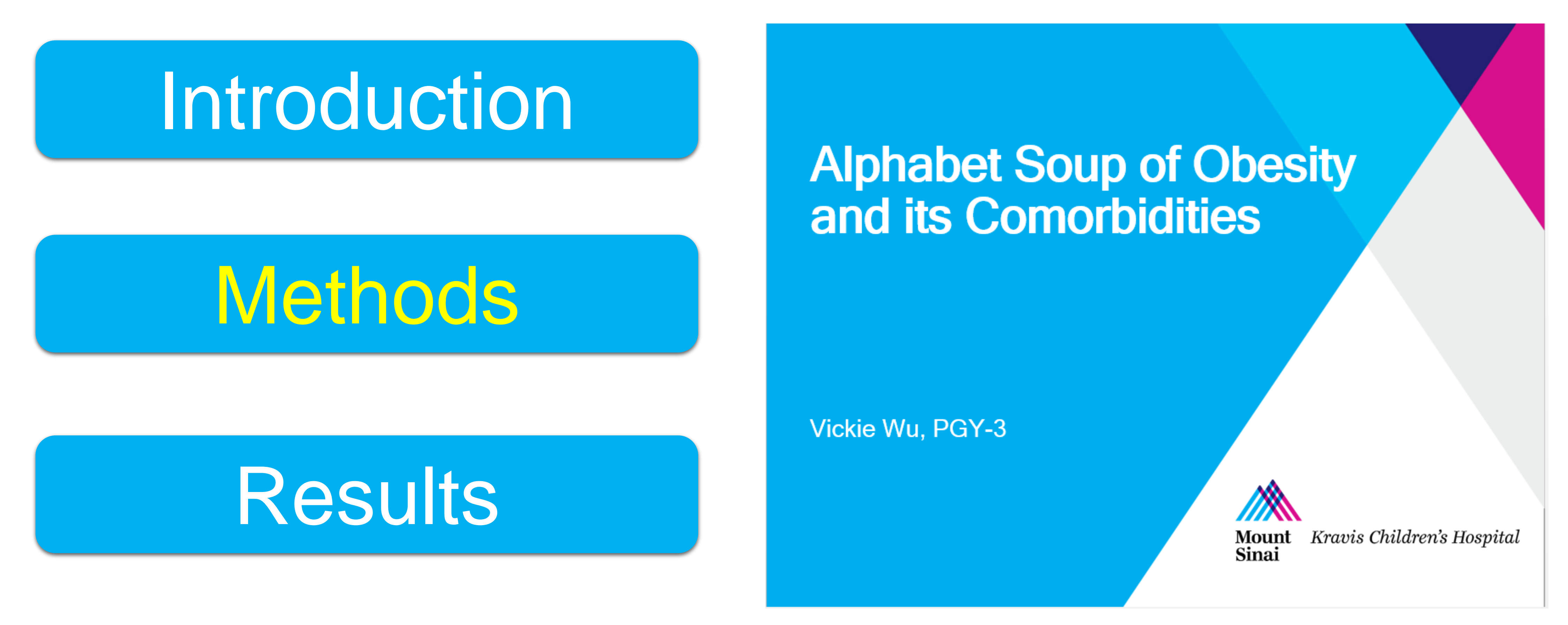

Conclusions

References

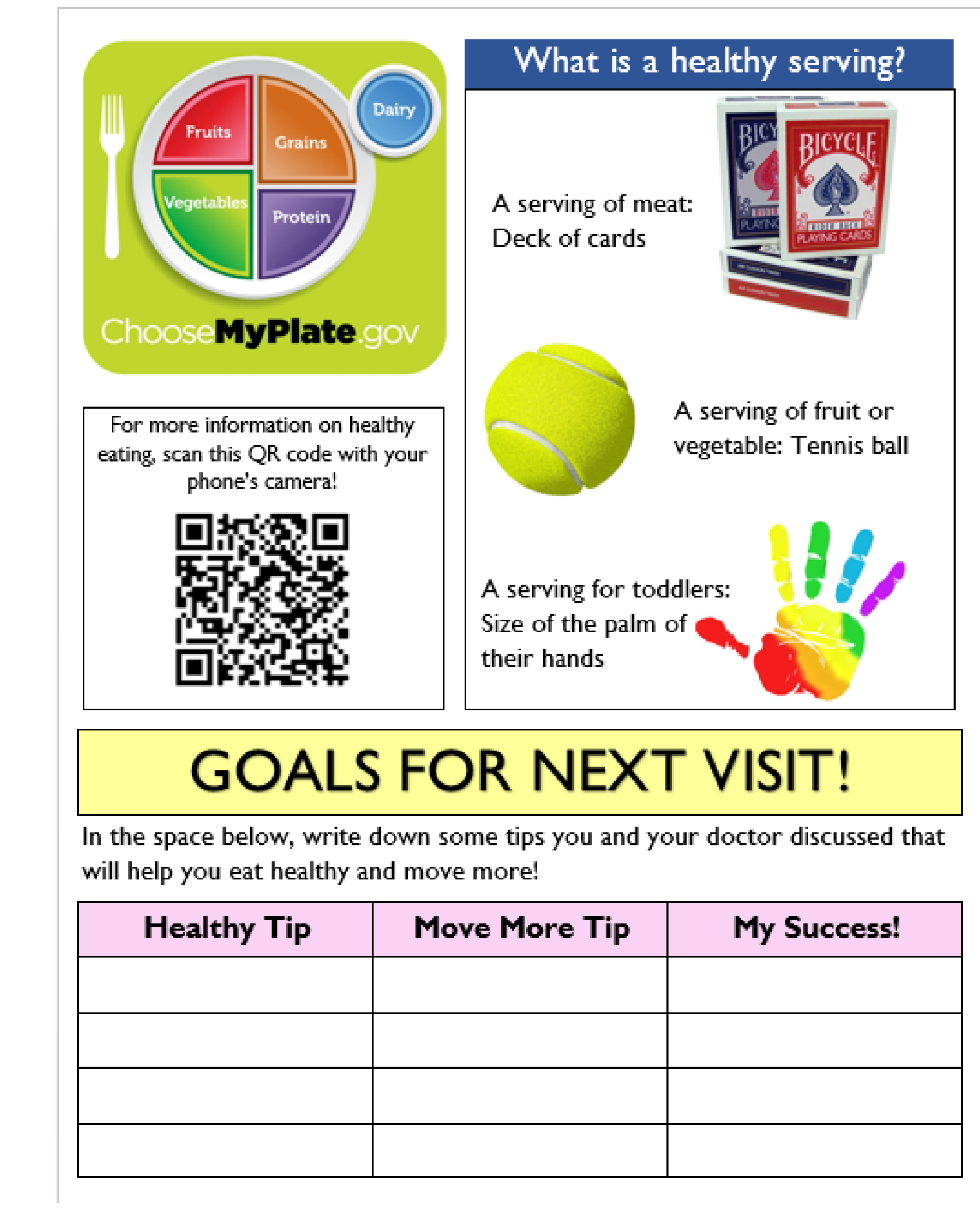

5432 10 Healthy Lifestyle Tips

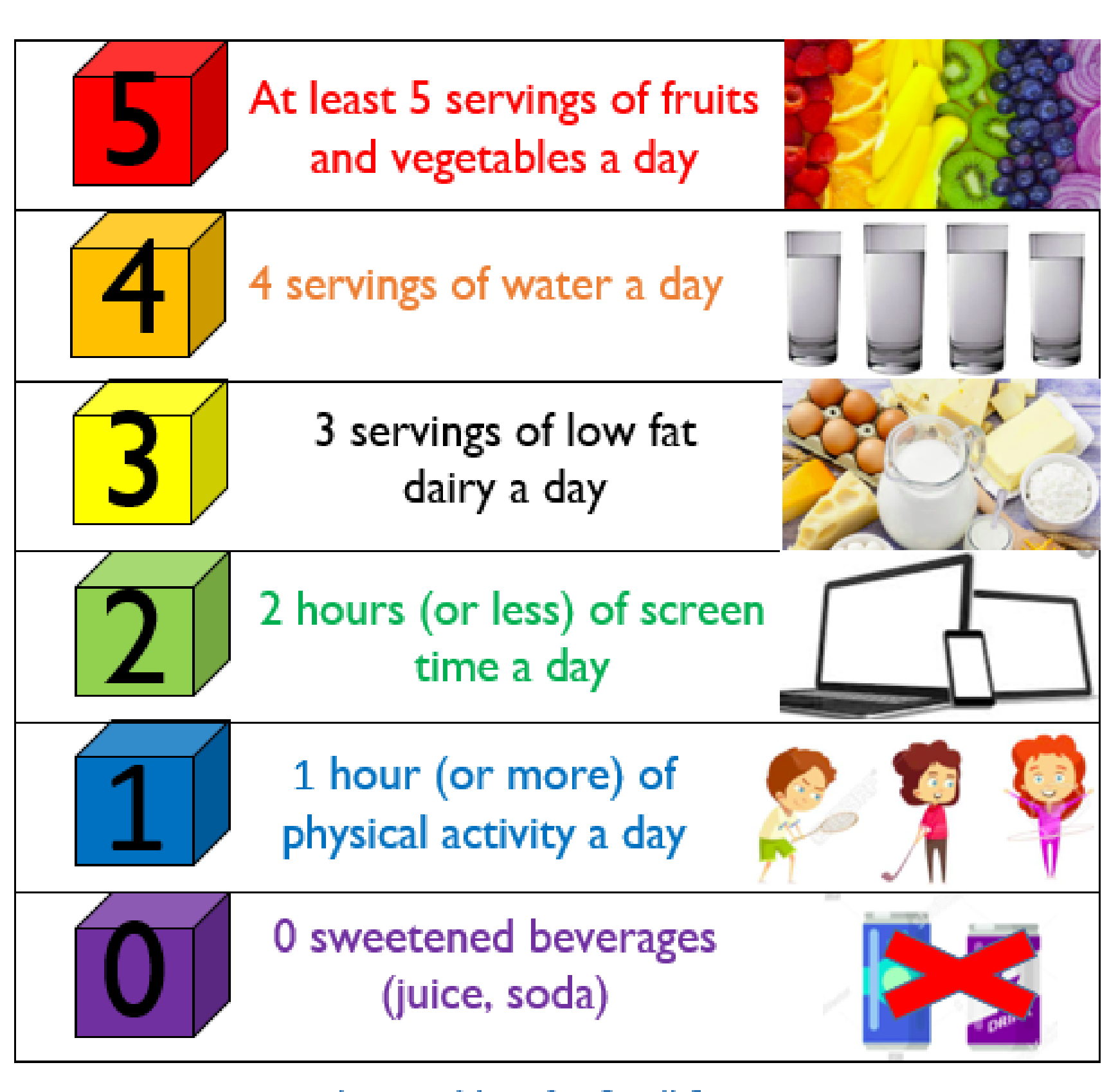

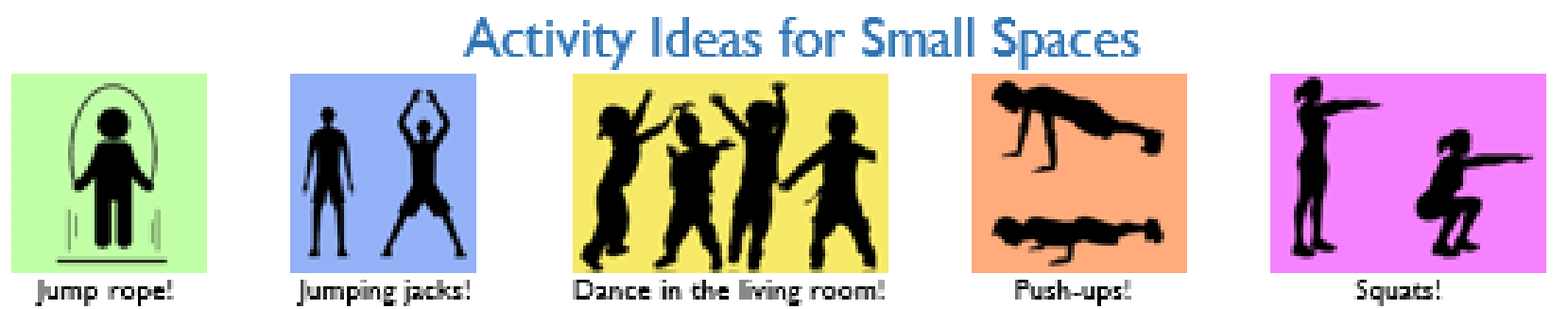

₹ BestPractice Advisories ,

"This patient's BMI percentile for age and sex is greater than or equal to 85 th percentile. Please complete the following:

1. Complete a nutrition and physical activity assessment (Suggestion: use the Smartphrase .nutritionbehaviorassessment).

(1) 2. Order screening labs if applicable (fasting glucose/HbA1c, ALT, AST, lipid panel).

Jump to Growth Chart List
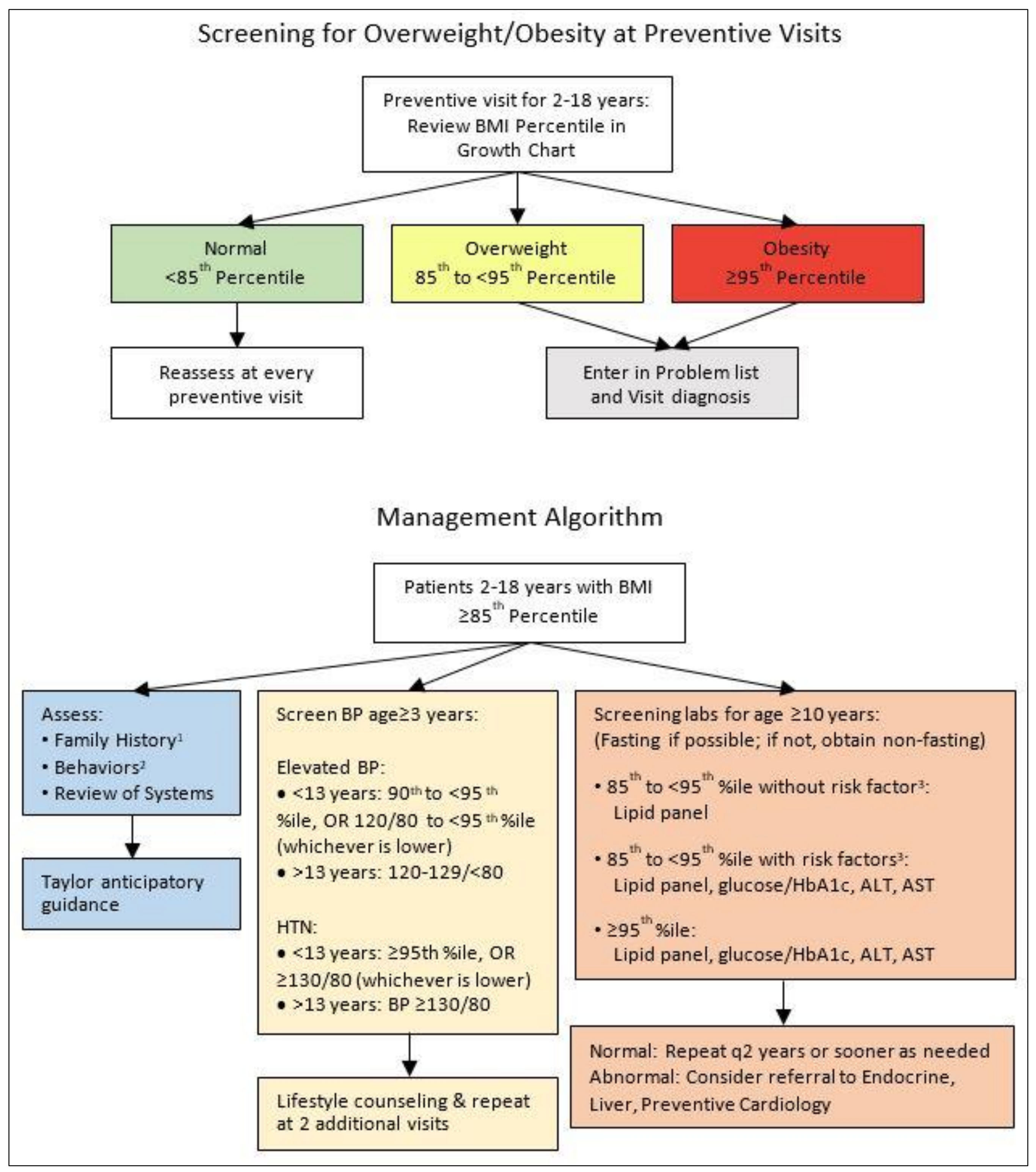


\section{Improving Documentation of Pediatric Overweight and Obesity by Resident Physicians}

Icahn

Medicine at

Mount

Sinai

\section{Introduction}

\section{Methods}

\section{Results}

Conclusions

References
1490 patients 2-

18 years old

presented for preventive visit

667 patients with overweight or obesity $(44.8 \%)$

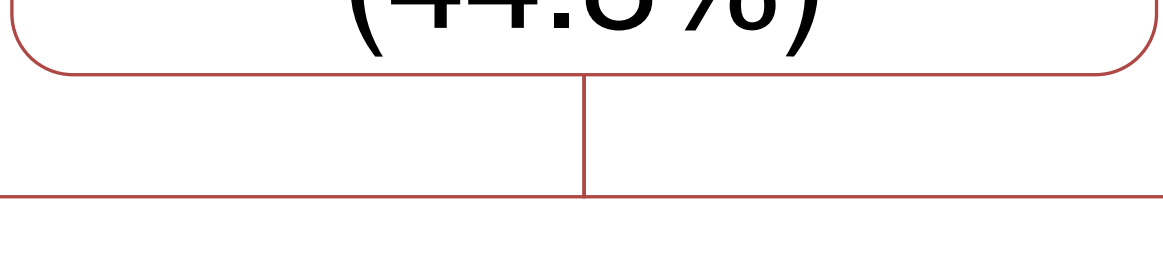

392 patients in pre-

intervention group
275 patients in postintervention group
Baseline demographics and clinical characteristics, pre- and post-intervention.

\begin{tabular}{|c|c|c|c|c|}
\hline & $\begin{array}{l}\text { All Patients } \\
(n=667)\end{array}$ & $\begin{array}{l}\text { Pre-Intervention } \\
\quad(n=392)\end{array}$ & $\begin{array}{l}\text { Post-Intervention } \\
\quad(n=275)\end{array}$ & $P$-value \\
\hline & Mean \pm SD or $\mathrm{N}(\%)$ & Mean \pm SD or $N(\%)$ & Mean \pm SD or $N(\%)$ & \\
\hline Age & $9.0 \pm 4.4$ & $8.7 \pm 4.3$ & $9.4 \pm 4.5$ & 0.057 \\
\hline Age Group & & & & 0.057 \\
\hline Age $2-5$ & $196(29.4)$ & $125(31.9)$ & $71(25.8)$ & \\
\hline Age $6-11$ & $254(38.1)$ & $153(39.0)$ & $101(36.7)$ & \\
\hline Age $12-18$ & $217(32.5)$ & $114(29.1)$ & $103(37.5)$ & \\
\hline Sex & & & & 0.389 \\
\hline Male & $377(56.5)$ & $227(57.9)$ & $150(54.5)$ & \\
\hline Female & $290(43.5)$ & $165(42.1)$ & $125(45.5)$ & \\
\hline BMI Status & & & & 0.226 \\
\hline $\begin{array}{r}\text { Obesity } \\
(\geq 95 \text { th percentile })\end{array}$ & $421(63.1)$ & $240(61.2)$ & $181(65.8)$ & \\
\hline $\begin{array}{r}\text { Overweight } \\
\left(85^{\text {th }} \text { to }<95^{\text {th }}\right. \\
\text { percentile })\end{array}$ & $246(36.9)$ & $152(38.8)$ & $94(34.2)$ & \\
\hline Ethnicity & & & & 0.385 \\
\hline Hispanic White/Black & $6(0.9)$ & $4(1.0)$ & $2(0.7)$ & \\
\hline Non-Hispanic Black & $235(35.2)$ & $148(37.8)$ & 87 (31.6) & \\
\hline Non-Hispanic White & $19(2.8)$ & $11(2.8)$ & $8(2.9)$ & \\
\hline Other & $407(61.0)$ & $229(58.4)$ & $178(64.7)$ & \\
\hline $\begin{array}{l}\text { No. of Patients per } \\
\text { Resident Year }\end{array}$ & & & & 0.184 \\
\hline PGY-1 & $211(31.6)$ & $125(31.9)$ & $86(31.3)$ & \\
\hline PGY-2 & $233(34.9)$ & $137(34.9)$ & 96 (34.9) & \\
\hline PGY-3 & $199(29.8)$ & $121(30.9)$ & $78(28.4)$ & \\
\hline PGY-4 \& PGY-5 & $24(3.6)$ & $9(2.3)$ & $15(5.5)$ & \\
\hline
\end{tabular}




\section{Improving Documentation of Pediatric Overweight and Obesity by Resident Physicians}

\section{Introduction}
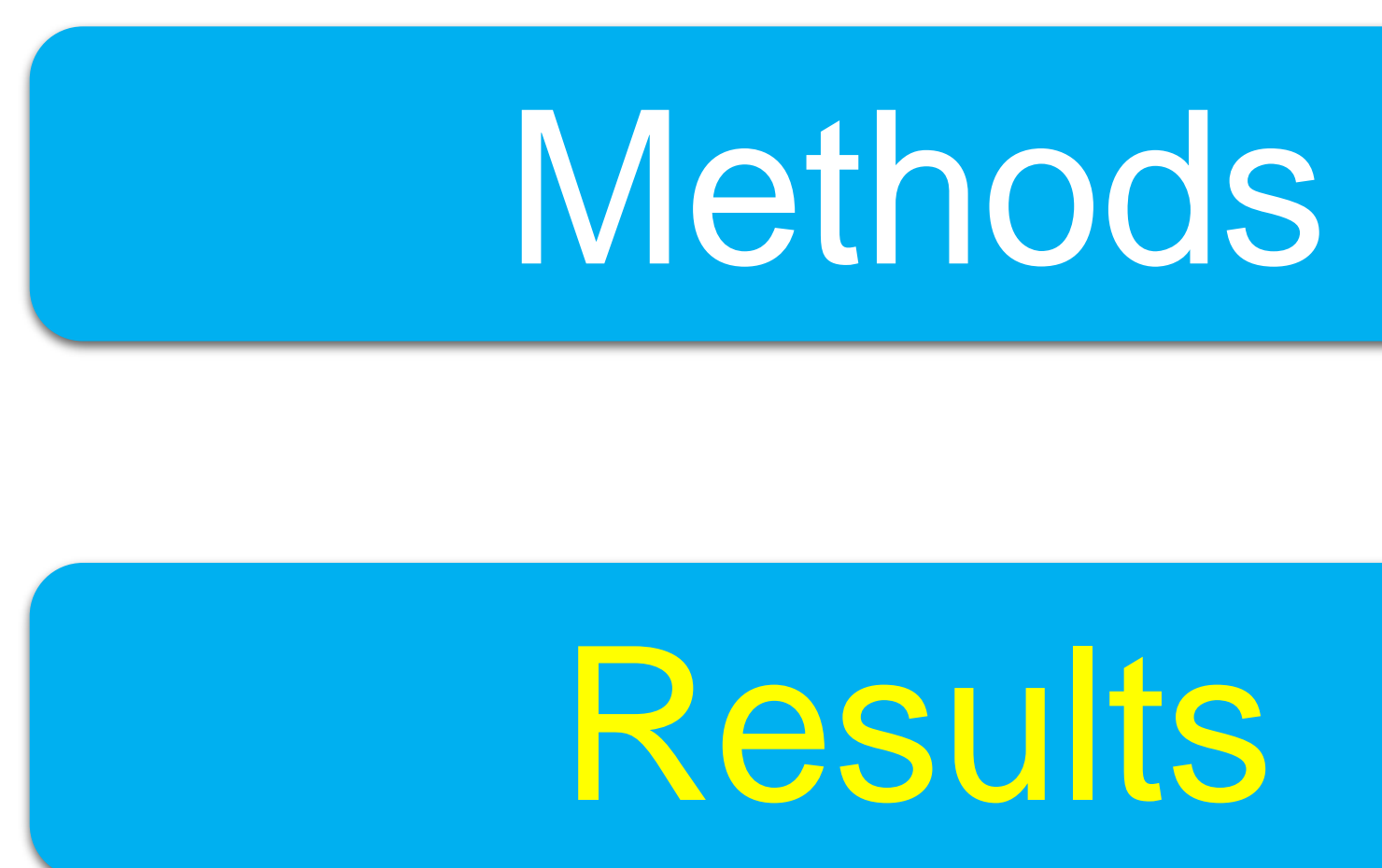

\section{Conclusions}

References

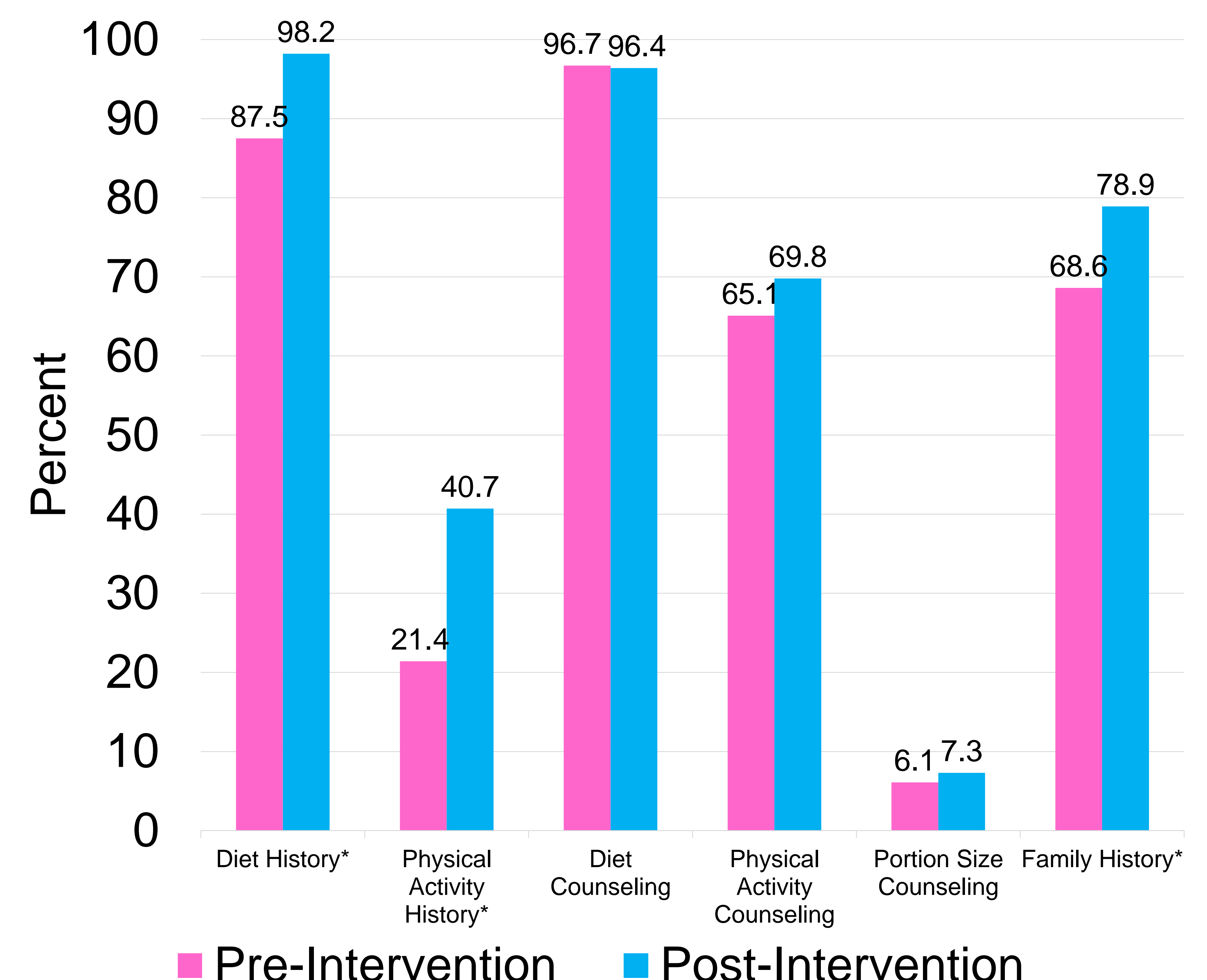

Percentage of charts with documentation of outcome of interest, pre- versus post-intervention.

* Indicates significant difference $(p<0.05)$ between preand post-intervention.

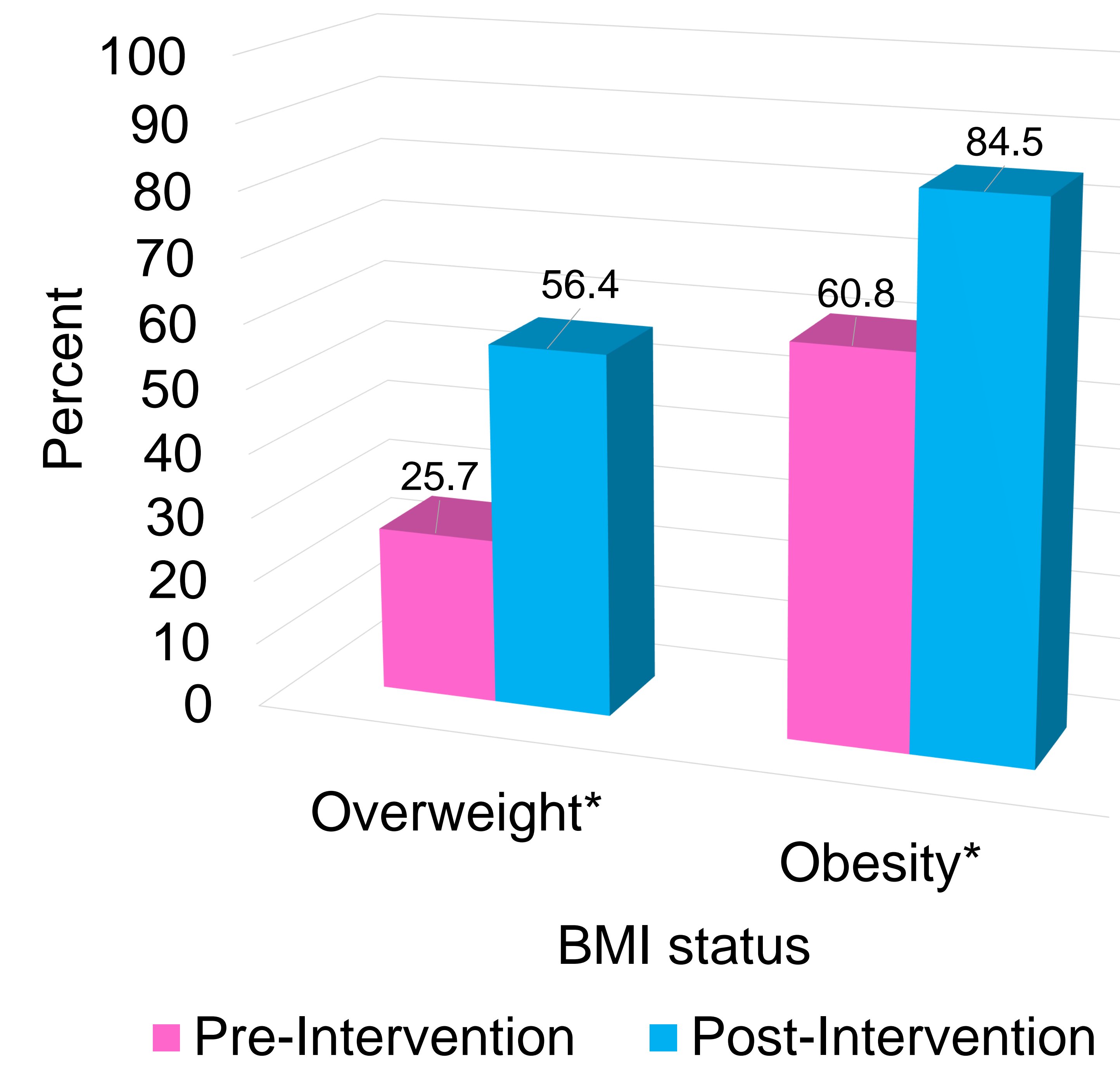

Pre- and post-intervention correct diagnosis rates for patients with overweight and obesity.

* Indicates significant difference $(p<0.0001)$ between preand post-intervention. 


\section{Improving Documentation of Pediatric Overweight and Obesity by}

Resident Physicians

Vickie Wu, MD; Carolyn Rosen, MD; Leora Mogilner, MD

Introduction

Methods

Results

Conclusions

References
- Implementation of resident-focused educational interventions improved residents' diagnosis of overweight and obesity but not frequency of counseling.

-Additional efforts are needed to further boost diagnosis rates and improve counseling efforts, and further studies will ascertain whether this then translates into positive behavior changes and improved clinical outcomes. 


\section{Improving Documentation of Pediatric Overweight and Obesity by}

Resident Physicians

\section{Introduction}

\section{Methods}

\section{Results}

\section{Conclusions}

\section{References}

- Hales CM, Fryar CD, Carroll MD, et al. Trends in obesity and severe obesity prevalence in US youth and adults by sex and age, 2007-2008 to 2015-2016. JAMA 2018;319(16):17235.

- O'Brien SH, Holubkov R, Reis EC. Identification, evaluation, and management of obesity in an academic primary care center. Pediatrics 2004;114(2):e154-9.

- Patel Al, Madsen KA, Maselli JH, et al. Underdiagnosis of pediatric obesity during outpatient preventive care visits. Acad Pediatr 2010;10(6):405-9.

- Rausch JC, Perito ER, Hametz P. Obesity prevention, screening, and treatment: practices of pediatric providers since the 2007 expert committee recommendations. Clin Pediatr (Phila) 2011;50(5):434-41.

- Reyes I. An evaluation of the identification and management of overweight and obesity in a pediatric clinic. J Pediatr Health Care 2015;29(5):e9-14.

- Skinner AC, Ravanbakht SN, Skelton JA, et al. Prevalence of obesity and severe obesity in US children, 1999-2016. Pediatrics 2018;141(3).

- Staiano A, Marker A, Liu M, et al. Childhood obesity screening and treatment practices of pediatric healthcare providers. J La State Med Soc 2017;169(1):2-10. 